\title{
GRALHAS EM MACHADO DE ASSIS \\ BIBLIOFILIA E ESTUDO DAS FORMAS MATERIAIS \\ DE EDIÇÃO, CORREÇÃO E CIRCULAÇÃO DE UMA OBRA
}

Thiago Mio Salla 
RESUMO A partir do exame do célebre erro tipográfico que consta da segunda edição das Poesias Completas de Machado de Assis, publicada em 1902, o presente artigo busca examinar as particularidades relativas ao trabalho de publicação e correção desse livro que desperta o desejo dos bibliófilos. Ao longo de tal processo, procura-se lançar luz sobre a trajetória do obscuro Eduardo Lemos, funcionário da casa Garnier que manualmente corrigiu os exemplares ainda não vendidos da obra, bem como examinar as diferentes implicações da gralha em questão. Assim, de modo pontual, pretende-se promover a aproximação entre particularidades inerentes à bibliofilia e o estudo das formas materiais de inscrição e transmissão da cultura livresca.

MACHADO DE ASSIS - LIVRARIA

E EDITORA GARNIER • REVISÃO DE TEXTO • BIBLIOFILIA.
"GRALHAS" [TYPOGRAPHICAL ERRORS]

IN MACHADO DE ASSIS:

BIBLIOPHILIA AND STUDY OF

THE MATERIAL FORMS OF EDITING, CORRECTION AND CIRCULATION OF A BOOK"

ABSTRACT Based on the examination of the famous typographical error that appears in the second edition of Machado de Assis, Poesias Completas, published in 1902, the present article seeks to examine the particularities related to the work of publication and correction of this book that arouses the desire of bibliophiles. Throughout this process, we aim to shed light on the trajectory of the obscure Eduardo Lemos, an employee of the publishing house Garnier, who manually corrected the unsold copies of the book, and examine the different implications of the typo committed in that case. Thus, in a specific way, we intended to promote the approximation between particularities inherent to the bibliophilia and the study of the material forms of inscription and transmission of the book culture.

MACHADO DE ASSIS - BOOKSTORE AND PUBLISHING HOUSE GARNIER • PROOFREADING - BIBLIOPHILIA.

\section{SOBRE 0 AUTOR}

Thiago Mio Salla é doutor em Ciências da Comunicação e em Letras pela Universidade de São Paulo. Enquanto docente e pesquisador da ECA-USP e do Programa de Pós-graduação em Estudos Comparados de Literaturas de Língua Portuguesa da FFLCH-USP, dedica-se às áreas de Literatura Brasileira, Teorias e Práticas da Leitura e Editoração. Entre outros trabalhos, publicou o livro Garranchos - Textos Inéditos de Graciliano Ramos (Record, 2012) e Graciliano Ramos e a Cultura Política: Mediação Editorial e Construção do Sentido (Edusp, 2016). 
Em crônica de 17 de julho de 1864, publicada no Diário do Rio de Janeiro, Machado de Assis ressaltava que sempre tinha receio de escrever as palavras "parlamento" e "parlamentar", pois um descuido tipográfico poderia levar a um trocadilho involuntário. "Sistema parlamentar, composto às pressas, pode ficar um sistema para lamentar" ${ }^{2}$. No transcorrer desse mesmo texto, Machado alude ao caso de um suposto poeta que nunca teria publicado um verso que não tivesse sido estropiado pela impressão. Desenganado com o péssimo trabalho executado pelos tipógrafos em geral, o tal sujeito afirmava que não publicaria mais impressos, mas tão somente manuscritos ${ }^{3}$.

Quase quarenta anos depois, o próprio Machado de Assis teve motivos para se lamentar (sem trocadilho) diante de um erro tipográfico

1. Para a confecção deste artigo, contei com a generosa ajuda de Ubiratan Machado. Gostaria de deixar registrados meus agradecimentos a esse notável estudioso da história do livro e da edição no Brasil.

2. Machado de Assis, Obra Completa, p. 142.

3. Idem, ibidem. Todavia, convém assinalar que o sagaz narrador da crônica percebe o ardil do desalentado poeta, que, deliberadamente, autorizava os tipógrafos a cometerem erros tipográficos em suas produções como meio de mascarar sua incapacidade criativa. 
que consta da segunda edição de suas Poesias Completas, obra impressa em Paris, em 1902, pela Garnier, que reunia seus três primeiros livros de poemas, Crisálidas, Falenas e Americanas, e acrescentava a tal conjunto a então última produção do autor no gênero, Ocidentais ${ }^{4}$. O deslize em questão, tido como um dos mais infelizes e célebres da literatura brasileira ${ }^{5}$ e inexistente na edição princeps de 1901, aparece logo na "Advertência". Nessa parte, ao se referir à exclusão do prefácio de Caetano Filgueiras presente no livro Crisálidas, Machado se justificava dizendo que assim procedia, pois a afeição por ele manifesta pelo referido amigo "cegara o juízo" deste. Todavia, devido a uma gralha, o "e" do verbo "cegara” deu lugar a um "a”, resultando na palavra "cagara”.

Diante de tal descuido de revisão, o poeta Alberto de Oliveira destaca, na marginália de seu exemplar das Poesias Completas, que Macha-

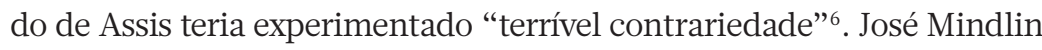
dizia não saber como o autor de Dom Casmurro, ao perceber o deslize, não teve um ataque de apoplexia ${ }^{7}$. Rubens Borba de Moraes, por sua vez, cogita a respeito da cara feita pelo "pudibundo autor vendo esse erro

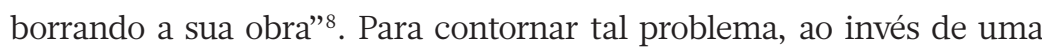
errata, realizou-se, nos exemplares ainda não vendidos da obra, a raspagem da letra "a" e, em seguida, o desenho, à caneta nanquim, da letra "e". Especulou-se, inicialmente, que o próprio Machado teria feito, manualmente, a correção ${ }^{9}$, mas hoje se sabe que tal tarefa coube a Eduardo Lemos, então funcionário da Livraria Garnier no Rio de Janeiro.

Em vista das particularidades da trajetória editorial das Poesias Completas de Machado, chamam a atenção a primeira edição da obra, publicada em 1901 sem a referida gralha, mas, sobretudo, as duas variantes da segunda edição da coletânea, ou seja, aquela em que o erro ainda persiste e aquela na qual ele foi corrigido à mão. Aliás, os exemplares da segunda edição, que trazem tais fatores acidentais, contrariando o pressuposto fundado na noção de antiguidade de que a edição princeps seria a mais valiosa $^{10}$, constituem-se em verdadeiras raridades e são cobiçados por

\footnotetext{
4. Por mais que, oficialmente, François-Hypollite Garnier figurasse como livreiro-editor das Poesias Completas, destaque para a efetiva participação de Machado na concretização do projeto. "Preparando, ordenando, exercendo suas percepções literárias, o autor revelou-se poeta, editor e crítico das Poesias Completas" (Fabiana Gonçalves, De Poeta a Editor de Poesia: A Trajetória de Machado de Assis para a Formação de Suas Poesias Completas, p. 129).

5. Pedro Corrêa do Lago, Brasiliana Itaú - Uma Grande Coleção Dedicada ao Brasil.

6. Apud Josué Montello, Diário da Manhã, p. 339. Agradeço ao bibliotecário chefe da Biblioteca Acadêmica Lúcio de Mendonça da ABL, Luiz Antônio de Souza, pelo envio das páginas iniciais do exemplar da primeira edição das Poesias Completas de Machado que pertenceu ao poeta Alberto de Oliveira.

7. José Mindlin, Uma Vida entre Livros, p. 29

8. Rubens Borba de Moraes, O Bibliófilo Aprendiz, p. 104.

9. José Mindlin, op. cit., p. 29.

10. Rubens Borba de Moraes, op. cit., p. 101.
} 
MACHADO DE ASSIS

DA ACADEMIA BHAZILEIRA

\section{POESIAS}

COMPLETAS

\section{H. GARNIER, LIVREIR0-EDITOR}

71-73, RUA DO OUVIDOR, 71-73 | 6 , RUE DES SAINTS-PÈres, 6 RIO DE JANEIRO
Página do exemplar da primeira edição das Poesias Completas de Machado de Assis que pertenceu a Alberto de Oliveira. Biblioteca da Academia Brasileira de Letras. Na página apresentada, o poeta faz o seguinte comentário: "Cegara há alguns exemplares desta primeira edição [na verdade, da segunda] em que por lamentável descuido de revisão, o e d[e] cegara foi substituído por a. Soube que Machado experimentou com isso terrível contrariedade.
Capa da segunda edição das Poesias

Completas de Machado de Assis.

Exemplar pertencente à $B B M-U S P$.

$$
\text { - vi - . }
$$

Não deixo esse prefacio, porque a affeição do meu $\gamma$ defunto amigo a tal extremo lhe cegára o juizo que não viria a ponto reproduzir aqui aquella saudação inicial. A recordação só teria valor para mim. Baste aos curiosos o encontro casual das datas, a daquelle, 22 de Julho de 1864, e a deste.

Rio, 22 de Julho de 1900.

\section{Machado de Assis.}

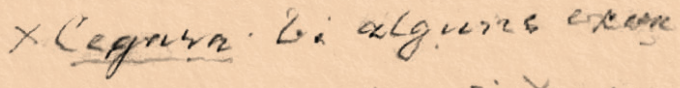

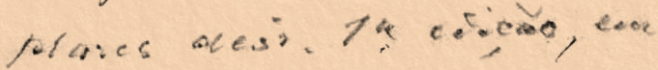

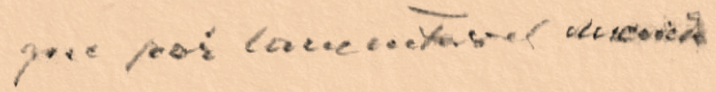

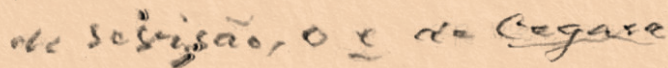

$$
\begin{aligned}
& \text { for serbstedecid, pos a, Sorrbx }
\end{aligned}
$$

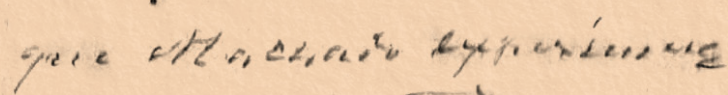

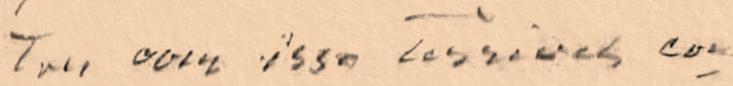

$$
\begin{aligned}
& \text { Cyaticetaser }
\end{aligned}
$$


colecionadores. Considerando-se o fato de que poucos livros com a embaraçosa faute d'impression circulam pelos antiquários, estes são caros e disputadíssimos por bibliófilos e bibliômanos brasileiros. Mas os que contam com as emendas feitas manualmente não ficam atrás ${ }^{11}$.

Não por acaso, na Biblioteca Brasiliana Guita e José Mindlin - BBM-USP, encontram-se exemplares da edição princeps e dos dois estados da segunda edição, isto é, com a "palavra feia" e com a correção dela feita à mão ${ }^{12}$. Mindlin se lembra de quando o poeta João Cabral de Melo Neto, que não conhecia a trajetória da edição das Poesias Completas de Machado, esteve em sua residência e estranhou a justaposição de três exemplares da referida obra na estante de sua brasiliana ${ }^{13}$, acervo que hoje pertence à Universidade de São Paulo.

\section{- vi -}

Não deixo esse prefacio, porque a affeição do meu $x$ defunto amigo a tal estremo the cegára o juizo que nao viria a ponto reproduzir aqui aquella saudação inicial. A recordação só teria valor para mim. Baste aos curiosos o encontro casual das datas, a daquelle, 22 de Julho de 1864, e a deste.

Rio, 22 de Julho de 1900.

\section{Machado de Assis.}

Página da "Advertência" da primeira edição das Poesias Completas (1901) de Machado de Assis, sem o erro tipográfico. BBM-USP.

11. Marcos Barrero, “Um Escritor Incompreendido”, O Estado de S. Paulo, 24 set. 1998, p. 4 (Caderno 2).

12. Em tal acervo, há ainda um exemplar do que se imagina ser a terceira edição da referida obra. Nela não se fazem mais presentes o famigerado erro e a posterior emenda deste à mão. Convém ainda assinalar que, no colofão desse volume, incluído na "Coleção dos Autores Célebres da Literatura Brasileira" da Livraria Garnier, tem-se a indicação da data 13.10.1924.

13. José Mindlin, op. cit., p. 29. 
Não deixo esse prefacio, porque a affeiçào do meu defunto amigo a tal extremo lhe cagára o juizo que não viria a ponto reproduzir aqui aquella saudação inicial. A recordação só teria valor para mim: Baste aos curiosos o encontro casual das datas, a daquelle, 22 de Julho de 1864, e a deste.

Rio, 22 de Julho de 1900.

Machado de Assis.

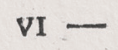

Não deixo esse prefacio, porque a affeição do meu defunto amigo a tal extremo lhe cegára o juizo que não viria a ponto reproduzir aqui aquella saudação inicial. $A$ recordação só teria valor para mim. Baste aos curiosos o encontro casual das datas, a daquelle, 22 de Julho de 1864, e a deste.

Rio, 22 de Julho de 1900.

Machado de Assis. 


\section{EDUARDO LEMOS: 0 LIVREIRO CORRETOR}

A atribuição ao próprio Machado da referida emenda a nanquim, por mais que tenha caráter lendário, não deixa de decorrer do rotineiro apagamento dos agentes responsáveis, entre outros aspectos, pela revisão e preparação de um texto. Em regra, tendo em vista o usual privilégio concedido para o produto final, e não para a práxis discursivo-editorial responsável por sua realização, os reparos costumam ser incorporados à instituição de autoria, e a ação do revisor, apagada. Não por acaso, a raspagem e a correção do primeiro "a” de "cagara", ainda mais por se tratar de uma marcação aparente que difere das habituais emendas feitas por um revisor em estágios preliminares da passagem da obra ao livro, foram atribuídas por muitos intelectuais a Machado.

Todavia, como já se mencionou, o responsável por tal ajuste em parte dos exemplares da segunda edição das Poesias Completas de Machado foi Eduardo Lemos, então caixeiro e depois gerente da Livraria Garnier. A ratificação de tal informação, que procurou pôr fim à lenda de que coubera ao autor de Dom Casmurro a feitura da emenda, deve-se ao próprio Lemos em atendimento a uma demanda de Galante de Sousa:

Rio de Janeiro, 2 de setembro de 1952

Ilmo. Sr. José Galante de Sousa

Nesta.

Atendendo ao seu pedido verbal declaro que havia, no prefácio de Poesias Completas de Machado de Assis, um erro gravíssimo, arrepiante é melhor, praticado na revisão: - na passagem em que dizia "cegara o juízo", um cochilo do revisor deixou passar a troca do "e" por um "a"... formando uma palavra suja.

Existem exemplares nas mãos dos amigos do livro com a letra refeita a nanquim, cujo trabalho foi executado por mim, e outros, com a palavra suja, que passaram por fora de minha vigilância.

Sem mais

(a). Eduardo Lemos ${ }^{14}$. 
Mas quem teria sido esse funcionário da Garnier? Na contramão do silenciamento dos diferentes profissionais e ações prévias que integram o processo editorial, condição costumeira ao longo da história do livro e da edição ainda mais em se tratando do ato de emendar, conviria conhecer minimamente quem foi Eduardo Lemos para depois retornarmos à edição das Poesias Completas de Machado na qual consta o famigerado erro tipográfico.

Em sessão da Academia Brasileira de Letras (ABL) ocorrida em 17 de julho de 1952, o imortal Clementino Fraga, a propósito do jubileu de Eduardo Lemos, presta uma homenagem a tal "enamorado das letras", amigo de cuja ternura a casa de Machado de Assis "teve sempre as provas mais desprendidas”.

Sem nada querer de nós, nem voto, nem benesses, Eduardo Lemos sempre crepitou de entusiasmo pelas justas acadêmicas no ambiente em que viveu, como livreiro e editor, dia por dia, durante cinquenta anos, em contato com homens de letras, e como bastardo dessa família intelectual, sua privança com alguns dos nossos maiores, legitimamente o acredita no penhor de nossa cordialidade ${ }^{15}$.

Nesse mesmo discurso, Fraga assinala que Eduardo Lemos entrou como empregado da Livraria Garnier em 1900, data que marca sua aproximação de Machado de Assis, assíduo frequentador da livraria. Segundo relembra o próprio Lemos, em entrevista concedida a David Nasser, o autor das Memórias Póstumas costumava chegar à Garnier todos os dias, sempre depois do almoço, sentava-se em uma cadeira, perto de uma coluna de ferro, e perguntava com a voz macia “quais são as novidades?"16 Ficava por lá até o fechamento do estabelecimento, conversando com um grupo de amigos, entre os quais se encontravam, entre outros, Alberto de Oliveira e João Ribeiro. Por vezes, deparava-se, na livraria, com um grupo de irreverentes poetas simbolistas, que se dirigia à Garnier com o propósito de hostilizar escritores mais velhos e chamar as atenções para $\mathrm{si}^{17}$. Lemos recorda-se do episódio em que sobre a cadeira em que Machado costumava sentar fora deixado um exemplar de livro que acabara

\footnotetext{
15. Clementino Fraga, "Palavras do Senhor Clementino Fraga", p. 12.

16. Eduardo Lemos, "O Homem da Porta da Garnier". Para além da convivência diária travada com Machado de Assis no tempo em que era funcionário da Livraria Garnier, Eduardo Lemos dizia conhecer o autor das Memórias Póstumas de um período anterior. O pai de Lemos, João Francisco Lemos, que costumava frequentar a Tipografia Dupont, apresentou-o "ao doutor Machado, um brilhante poeta".

17. Ubiratan Machado, História das Livraria Cariocas, p. 147
} 
de publicar com a seguinte dedicatória: "Mais um maçudo do maçudo Machado".

O então funcionário da Garnier ainda rememora, na referida entrevista $^{18}$, uma tarde em que Machado lhe perguntou o que diziam de sua obra. O caixeiro, cheio de coragem, respondeu que não a compreendiam. O romancista teria se admirado com a resposta e, virando-se para Lemos, interrogou-0:

- E você?

- Nem eu, seu Machado.

- Vai buscar um de meus livros.

Apanhei o Quincas Borba na estante. O homem voltou à carga:

- Qual trecho em que você se atrapalhou?

E levou várias horas me explicando o sentido daquela obra. E, desde aquele dia até hoje, tenho meu ponto de vista: só no ano dois mil Machado será compreendido ${ }^{19}$.

Agripino Grieco, em referência ao tempo em que Lemos gerenciava a Garnier, trata este último como um sujeito petulante, responsável por tirar as cadeiras de lá para que Alberto de Oliveira e seus discípulos não mais se aboletassem nelas, "parolando horas e horas e talvez espantando os cobradores" ${ }^{20}$. Para além de tal postura, nessa condição de gerente, ao que parece, Lemos desempenhara atividades editoriais. Em reportagem publicada nos anos 1950, gabava-se de que o livro de maior sucesso que já havia lançado teria sido Impressões da Europa (Suíça, Itália e Espanha), de autoria do ex-presidente da República Nilo Peçanha. Conforme lembra Lemos, a obra, que veio a público em 1912, alcançou o "maior sucesso da época":

Pela primeira vez fez-se fila no Rio de Janeiro. E coisa curiosa, elas não estacionaram nos açougues, nem tampouco nos armazéns, e sim na porta da antiga Livraria Garnier, naqueles saudosos tempos em que pontificavam ali

18. Tal depoimento encontra-se recolhido no caderno de recortes sobre o centenário do Bruxo do Cosme Velho que consta da BBM-USP (cf. Machado de Assis, Primeiro Centenário - 1839-1939).

19. Eduardo Lemos, op. cit. Ainda nessa entrevista a David Nasser, Lemos destacava que, após a morte de Machado, teria editado um livro no qual Mário de Alencar reunira as poesias completas do bruxo. Em seguida ele menciona que houve um erro tipográfico na introdução da obra, o qual "degenerou num palavrão deste tamanho" (Idem). Além de ter sido o próprio Machado o autor e organizador de tal coletânea poética (Mário de Alencar se dedicou a coligir, em edições póstumas, crônicas, críticas e o teatro do fundador da ABL), o antigo caixeiro da Garnier ainda se equivoca ao tratar de suas diligências no sentido de corrigir o referido erro: sua função resumira-se a emendar manualmente os exemplares ainda não vendidos da segunda edição

das Poesias Completas, tal como foi aqui apresentado anteriormente.

20. Agripino Grieco, Memórias, p. 280. 


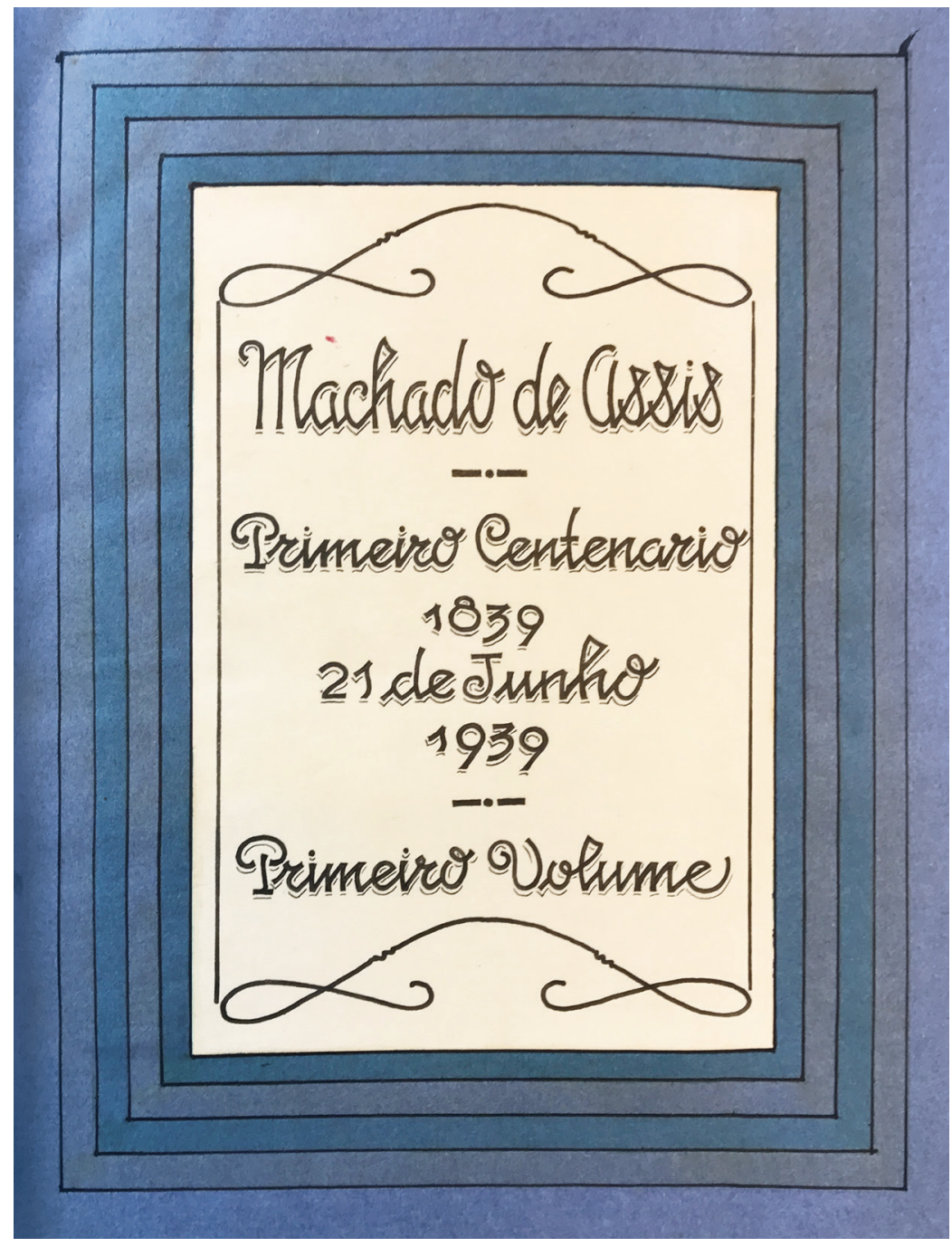


os mais altos expoentes das letras nacionais. Todos que tinham qualquer pretensão junto ao governo iam ao Catete levando um exemplar²1.

Quanto à sociabilidade intelectual, em decorrência de sua amizade com o Laudelino Freire, Eduardo Lemos teve, em dado instante, relativa influência eleitoral na ABL. Provavelmente em vista disso, tratava-se de uma presença constante na Casa de Machado de Assis. Clementino Fraga destaca que seria dele o recorde de comparecimento às recepções acadêmicas, nada menos de trinta, "sendo a primeira a que a assistiu a de Afonso Arinos ${ }^{22}$, levado ao Gabinete Português de Leitura, a convite de Machado. A última foi a de Getúlio Vargas”23.

A amizade com Laudelino Freire ainda lhe renderia outros frutos. Em 1922, indicado por tal filólogo, Eduardo Lemos participou da publicação do fac-símile da segunda edição do Dicionário de Língua Portuguesa (1813), de António de Moraes Silva, a qual foi elaborada em comemoração ao primeiro centenário da Independência pela Lito-Tipografia Fluminense ${ }^{24}$. Quinze anos depois, já à frente da editora A Noite S. A., o ex-funcionário da Garnier deu início à edição do Grande e Novíssimo Dicionário da Língua Portuguesa, dirigido por Laudelino Freire ${ }^{25}$, cujos cincos volumes foram lançados ao longo de cinco anos (1939-1944) ${ }^{26}$.

Nessa condição de gerente da editora A Noite, Eduardo Lemos era descrito como um "perfeito técnico da indústria e comércio do livro", atributos que faziam dele um herói e soldado pouco conhecido da "inteligência indígena" ${ }^{27}$. Em virtude de sua experiência de muitos anos e das amplas relações que construíra no mundo das letras, conheceria os gostos do público, "suas preferências, os gêneros literários que têm mais saída etc.” ${ }^{28}$. Sem se referir à passagem de Lemos por essa casa editorial, Agripino Grieco destaca que o ex-caixeiro

21. Mário Cordeiro, "Um Dicionário à Procura de Seus Autores", p. 11. De fato, o livro alcançou grande saída. Em quatro dias, a casa Garnier já havia vendido setecentos exemplares, e o restante da tiragem de cinco mil prometia se esgotar num curto espaço de tempo, considerando-se os pedidos que vinham dos Estados ("O Livro do Dia", Gazeta de Notícias, p. 1). Todavia, na referida reportagem, Eduardo Lemos se confunde ao destacar que o sucesso de vendas se deveu ao fato de Nilo Peçanha, quando do lançamento de Impressões da Europa, ocupar a cadeira da presidência. Na verdade, tal político esteve à frente do Governo Federal entre 1909 e 1910, e a referida obra foi lançada em 1912.

22. Escritor que tomou posse em 1901, na cadeira 40, em lugar de Eduardo Prado. Não o confundir com seu sobrinho Afonso Arinos de Melo Franco, que sucedeu José Lins do Rego na cadeira 25, em janeiro de 1958.

23. Clementino Fraga, op. cit., p. 12.

24. Idem, ibidem.

25. Segundo destaca o próprio Eduardo Lemos, o contrato de edição entre Laudelino Freire e a Editora A Noite deu-se em abril de 1937. Um ano depois o dicionarista veio a falecer (Mario Cordeiro, op. cit.).

26. Entre a edição de um e outro dicionário, Eduardo Lemos foi, em 1930, secretário-geral do general Tasso Fragoso, chefe da junta militar que governou o país durante alguns dias (Clementino Fraga, op. cit., p. 12).

27. “Uma Reportagem na Itália Constituiu um Grande Êxito de Livraria e de Crítica”, Correio Paulistano, p. 4. 
da Garnier teria se arrastado numa velhice melancólica, em cargos bem inferiores às suas pompas do período de gerente [da Garnier]" ${ }^{29}$. O memorialista ainda emenda: "os literatos que Eduardo Lemos irritava davam-no como português, e, embora ele se dissesse capixaba, a dicção o comprometia” ${ }^{30}$.

\section{GRALHAS EM SÉRIE}

Percorrida rapidamente a trajetória do obscuro Eduardo Lemos, ao se retomar a emenda por ele realizada no prefácio da segunda edição das Poesias Completas de Machado de Assis, percebe-se que a raspagem e a correção da letra "a” em "cagara” consistiram, de fato, em uma intervenção pontual e emergencial. Tal afirmação se baseia sobretudo no fato de que, quando se considera o todo dessa edição, verifica-se que ela apresenta uma série de outras gralhas deixadas de fora do trabalho corretivo efetuado por esse livreiro-editor, então caixeiro da Livraria Garnier na aurora do século xx.

Mais especificamente, a segunda edição das Poesias Completas de Machado, com seu famigerado erro tipográfico, na verdade, não passa de mera reimpressão da primeira edição da mesma obra datada de 1901. Ao se examinar a errata aposta ao final desta e cotejá-la com o miolo daquela, confirma-se que, de uma edição para a outra, nada foi alterado, com exceção da emenda feita manualmente na "palavra feia”. Tal corrigenda consigna ao todo 36 deslizes que deveriam ser corrigidos pelo leitor, quando da leitura da coletânea. Entre estes têm-se, sobretudo, pequenas gralhas quer pela troca, falta ou omissão de letras, quer por quebras inadequadas ou repetição de vocábulos, quer por problemas de acentuação.

Apesar de pequenos, tais deslizes acabam também se revelando danosos, sob muitos aspectos, para a imagem da editora e do poeta. Por exemplo, no soneto "Alencar", feito em homenagem ao romancista indianista, há um problema logo no título: ao invés de "Alencar”, tem-se "Alençar". Outro caso representativo pode ser observado no canto Xxv, do poema "Pálida Elvira". Nele, a interpelação à "leitora curiosa” dá lugar à "leitosa curiosa”. Assim, nessas ocorrências específicas, tanto a referência encomiástica ao autor de Iracema como a proposta de se dirigir ao enunciatário perdem a força em função das gralhas não corrigidas pela segunda edição ${ }^{31}$. 
As duas páginas com a errata que acompanha a primeira edição (1901) das Poesias Completas de Machado de Assis. Biblioteca Florestan Fernandes

(FFLCH-USP).

\section{ERRATA}

Pagina 3. E' no teu seio em vez de E no teu seio.

Pagina 9. limpidas em vez de limpadas.

Pagina 39. tens $e m$ vez de teus.

Pagina 50. no poente em vez de na poente.

Pagina 106. tu que vens em vez de tu que veus.

Pagina 116. não me illude em vez de não me illudo.

Pagina 131. a mão que implora o amor em vez de a mão que implora o omor.

Pagina 13t. Te ha de faltar em vez de T'u ha de faltar.

Pagina 150. Devo agora em vez de Devo agoro.

Ieitosa.

Pagina 151. Todavia a leitora em vez de Todavia a

Pagina 153. E' nossa em vez de E nossa.

Pagina 163. Fazer do em vez de Faz erdo.

Pagina 193. povoadas praias em vez de povoadas prias.

Pagina 199. o pio em vez de o pia.

Pagina 206. lança em vez de lanca.

1) ") atravez em vez de atrazez.

Pagina 218. E' como em vez de E como.

1) " vôa em vez de voa.

Pagina 219. embora $e m$ vez de embera.

Pagina 224. Vida é tudo, em vez de Vida é tudo.

$$
-2-
$$

Pagina 241 a ouvidos em vez de o ouvidos.

Pagina 243 fechar $e m$ vex de fachar.

Pagina 251. enchia em vez de encheia.

1) ") de vestes negras, em vez de do vestes negras.

Pagina 254. lusitano em vez de luzitano.

Pagina 294. Ama de egual em vez de Ama de qual.

Pagina 301 Abramos em vez de Abramo.

Pagina 310. E' mais em vez de $\mathrm{E}$ mais.

Pagina 315. deslembrado de tudo em vez de deslumbrado de tudo

Pagina 318. Sòem cá fóra $e m$ vez de Sôem ça fra

Pagina 320. Alencar em vez de Alençar

Pagina 336 Com os da frente em vez de com os os da frente.

Pagina 339. um braço em vez de em braço.

1) " e a vel-o em vez de e o vel o.

Pagina 356. Moça havia em vez de Moca havia.

Pagina 37ı. As moças ricas em vez de As moças rias. 
Além disso, o aproveitamento por parte da Garnier da composição utilizada na primeira edição deu margem a que, na segunda, surgissem novos erros, decorrentes, principalmente, do desgaste dos tipos e até mesmo do desaparecimento de letras ${ }^{32}$. De fato, sobretudo em final de linha, observam-se a falta de elementos que redundam em vocábulos quebrados ou, mesmo, deslizes de concordância e ainda erros de pontuação, tendo em vista a queda do sinal gráfico esperado. No exemplar da segunda edição das Poesias Completas de Machado de Assis que pertenceu a Mário de Andrade, o autor de Macunaíma faz a correção manual de alguns desses problemas ${ }^{33}$.

31. Curioso observar que mesmo os intelectuais responsáveis por tecer críticas severas às Poesias Completas de Machado não se valeram do apontamento dos erros tipográficos presentes nas edições da obra para atacar o fundador da ABL. Múcio Teixeira, por exemplo, elenca uma série de problemas relacionados não a fautes d'impression, mas, segundo ele, à fatura artística dos poemas recolhidos no livro: 140 deslizes com as "palavras assonantadas", vinte incorreções no emprego de palavras esdrúxulas ao fim de versos soltos e uma série de arbitrariedades cometidas nas estrofes rimadas. Por fim, menciona uma incorreção gramatical referente à concordância verbal num dos tercetos do poema "Uma Senhora que me Pediu Versos" - "Uma só das horas tuas / Valem um mês / Das almas ressequidas" - e, em seguida, destaca: "Assim, um só destes erros valem, ou deviam valerem, muitos bolos de palmatória nos seus longínquos tempos de aluno da escola régia do bairro da Saúde" (Múcio Teixeira, Poesias Completas, apud Ubiratan Machado, Machado de Assis: Roteiro da Consagração). Por seu turno, Sílvio Romero, depois de afirmar que o volume seria prova da carência de recursos do estro machadiano, registra o uso excessivo de quês por parte do fundador da ABL. No poema "A Mosca Azul", por exemplo, seriam dezoito quês, em dezesseis quadras (Sílvio Romero, Outros Estudos de Literatura Contemporânea, apud Ubiratan Machado, op. cit., p. 255).

32. Pesquisa de Filologia Fundação Casa de Rui Barbosa, "Sobre Esta Edição", em Machado de Assis, Poesias Completas, p. 11.

33. Para além de ele próprio emendar as gralhas presentes em seu exemplar da segunda edição das Poesias Completas de Machado, Mário de Andrade povoa o livro com uma série de anotações. Em linhas gerais, pode-se dizer que ele aproveita a leitura e a glosa do volume na produção do texto "Machado de Assis", datado de 1939. Na segunda parte desse ensaio, o escritor modernista discorre sobre a poesia do fundador da ABL. Se por um lado rebaixa a produção inicial deste e destaca que, com Ocidentais, ele teria levado a poesia às portas do degenerante Parnasianismo, por outro, exalta o poema "Última Jornada", descrito como "uma das mais belas criações do mestre e da nossa poesia" (Mário de Andrade, Aspectos da Literatura Brasileira, p. 97). 


\section{A ARTHUR DE OLIVEIRA, ENFER Mo}

\section{Sabes tu de um poeta enorme} Que andar não usa

No chão, e euja extranha musa, Que nunca dorme,

Calça o pé, melindroso e leve, Como uma pluma,

De folha e flor, de sol e neve, Crystal e espuma ;

E mergulha, como Leandro, A fórma rara

No Pó, no Sena, em Guanabara E no Scamandro;

Ouve a Tupan e escuta a Momo, Sem controversia,
Mário de Andrade acrescenta o "P" que falta na abertura da segunda linha da epígrafe do poema "La Marchesa de Miramar", que consta de seu exemplar da segunda edição das Poesias Completas de Machado de Assis. Biblioteca do IEB.

\section{LA MARCHESA DE MIRAMAR}

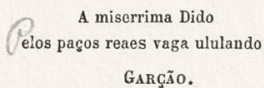

De quanto sonho um dia povoaste A mente ambiciosa,

Que te resta? Uma pagina sombria, A escura noite e um tumulo recente.

Ó abysmo! Ó fortuna! Um dia apenas Viu erguer, viu cair teu fragil throno. Meteoro do seculo, passaste, ó triste imperio, allumiando as sombras. A noite foi teu berço e teu sepulcro.

Da tua morte os goivos inda acháram. Frescas as rosas dos teus breves dias;

E no livro da historia uma só folha

A tua vida conta : sangue e lagrimas. 
E sonho o que nenhum mortal ha já sonhado, Mas o silencio amplo e calado,

Calado fica; a quietação quieta;

Só tu, palavra unica e dilecta,

Lenora, tu, como um suspiro escasso,

Da minha triste boca saes;

E o eco, que te ouviu, murmurou-te no espaço;

Foi isso apenas, nada mais.

Entro co' a alma incendiada.

Logo dopois outra pancada

Sôa um pouco mais forte; eu, voltando-me a ella :

"Seguramente, ha na janella

"Alguma cousa que sussura. Abramo/

" Eia, fồra o temor, eia, vejamos

“ A explicação do caso mysterioso

“ D'essas duas pancadas taes.

"Devolvamos a paz ao coração medroso

"Obra do vento e nada mais. "

Abro a janella, e de repente,

Vejo tumultuosamente

Um nobre corvo entrar, digno de antigos dias.

Não despendeu em cortezias

Um minuto, um instante. Tinha $o$ aspecto

De um lord ou de uma lady. E prompto e recto

Movendo no ar as suas negras alas,

Acima vôa dos portaes,

Trepa, no alto da porta, em um busto de Pallas;

Trepado fica, e nada mais. 
Todavia, o desgaste das matrizes de impressão não explicaria a passagem de "cegara” a "cagara” no prefácio da segunda edição da obra, isto é, não houve apagamento ou alteração de parte da letra na passagem do "e" ao "a", mas sim a troca do tipo. Daí a hipótese aventada por Antônio Carlos Secchin de que tal gralha específica poderia decorrer de fraude ou sabotagem: "Como pode ter uma palavra certa na primeira e ela aparecer errada na segunda? Era só botar na máquina e repetir a impressão" 34 . Difícil confirmar tal hipótese ${ }^{35}$. De todo modo, quer eventualmente por esse motivo, quer por estar o erro presente justo no prefácio, quer por resultar em uma "palavra feia" (algo que contrariara imenso a pudicícia do autor), o desvio em questão recebeu um tratamento diferenciado e cirúrgico por parte da editora, quando comparado com os deslizes recorrentes no miolo.

Em função desse conjunto de razões, a famigerada gralha, diferente das demais, não caberia numa errata. Tal paratexto (em geral impresso nas páginas finais da obra ou em folha separada) procura impor um sentido ao livro sem tocar na materialidade da inscrição, isto é, a corrigenda não emenda, mas apenas sublinha o erro, exercendo a vigilância e apelando a uma transformação imaterial da obra ${ }^{36}$ :

A errata pressupõe, a cada momento, um horizonte de correção, seja como meta final no sentido da qual se movimenta o livro, seja como regra que o limita nesse movimento; porque a errata interrompe para estabelecer ou restabelecer a regra, para corrigir ou regular, mesmo que a correção careça, por sua vez, de outra correção, mesmo que a regularização funcione ela mesma de modo irregular com relação à regra que lhe preside ${ }^{37}$.

O problema no prefácio das Poesias Completas, assim, seria de outra ordem. Demandava ser corrigido materialmente no transcurso da leitura, sem o risco de não ser percebido por quem passasse batido pela errata, que, por sinal, consta apenas da primeira edição da obra, e não da segunda.

Aliás, os problemas consignados na corrigenda presente na primeira edição teriam sido apontados pelo próprio Machado. Conforme

\footnotetext{
34. Bolívar Torres, "Livros com Erros Tipográficos São Cobiçados por Colecionadores".

35. Ubiratan Machado afirma não acreditar em tal hipótese de sabotagem, proposta por seu amigo Secchin. "Quem trabalhou em jornal ou gráfica, no tempo da composição manual de tipos, sabe que, muitas vezes, um determinado texto (mesmo guardado para reimpressão) era desfeito, para atender a uma situação de emergência, fornecendo, por exemplo (mero palpite) os tipos para outra composição. Isso explica a diferença entre a primeira e a segunda edição, apesar da presença da mesma composição em ambas as edições. Pode-se admitir até uma queda da gaveta que guardava o texto, exigindo sua recomposição" (Ubiratan Machado. Machado. [mensagem pessoal]. Mensagem recebida por Thiago Mio Salla em 17 jan. 2018).

36. Abel Barros Baptista, "A Reforma Hermenêutica. Acerca da Legibilidade de Dom Casmurro", em João Cezar de Castro Rocha, Nenhum Brasil Existe - Pequena Enciclopédia, p. 566.

37. Abel Barros Baptista, Autobibliografias, p. 142.
} 
lembra Grieco, além de receber míseros proventos a partir da venda de exemplares e dos direitos de publicação do conjunto de sua obra, ficava a seu encargo rever gratuitamente as provas de todos os seus livros ${ }^{38}$. No que concerne a tal empreitada, o autor das Memórias Póstumas se mostrava muito zeloso. Em carta a Magalhães de Azeredo datada de 28 de julho de 1899, por exemplo, revela seu trabalho na correção de Dom Casmurro: "Já devolvi as provas dos últimos capítulos, mas tendo de ler segundas provas do livro, conforme mandei pedir, não creio que antes de novembro possa ser exposto ao público" ${ }^{39}$. A esse mesmo interlocutor, quase dois anos depois (em 30 de junho de 1901), o fundador da ABL trata ainda da revisão das Poesias Completas:

Há de achar no fim uma longa errata, que não devia existir, se eu pedisse, como fiz aliás com outros livros impressos fora, segundas provas de tudo. O resultado foi aquela lista de erros. Talvez o livro as mereça. Em todo caso, a culpa foi minha ${ }^{40}$.

Se Machado se penitencia por não ter solicitado, diferentemente de seu procedimento habitual, as segundas provas do livro impresso em Paris, o que dizer do trabalho de revisão que caberia à editora Garnier? E mais: o que dizer do fato de as imperfeições consignadas na errata da primeira edição não terem sido corrigidas na segunda, a qual, pelo contrário, apresenta um índice mais elevado de problemas? Além disso, não era a primeira vez que a editora comprometia a reimpressão de uma das obras de Machado. É ele mesmo quem o diz, uma vez mais em diálogo missivístico com o amigo Magalhães de Azeredo:

A casa Garnier reimprimiu ultimamente um dos meus livros mais antigos, os Contos Fluminenses; fê-lo sem que eu houvesse revisto o trabalho, e (creio que por equívoco) sem aviso prévio, e sem lhe pôr a nota de que era edição nova. Por tudo isso não lhe mando um exemplar ${ }^{41}$.

Os referidos questionamentos, obviamente, depõem contra o labor editorial realizado pela Garnier. Todavia, não na esfera íntima, mas publicamente, o próprio Machado é o primeiro a reconhecer os méritos e progressos alcançados pela editora instalada no Brasil. Ao longo de

38. Agrippino Grieco, Machado de Assis, p. 140.

39. Machado de Assis, Correspondência de Machado de Assis com Magalhães de Azeredo, p. 181.

40. Idem, p. 224

41. Idem, p. 181. 
sua produção cronística, em diferentes registros do movimento editorial carioca, o escritor não se cansou de elogiar o trabalho realizado por Baptiste-Louis Garnier. Em crônica de 20 de junho de 1864, já sublinhava que os livros impressos por esse editor na França, diferentemente do que até então ocorria, não apresentavam mais recorrentes erros tipográficos. Tal fato demovia os argumentos contrários à qualidade editorial das impressões feitas em Paris. O romancista explicava que, para evitar eventuais gralhas em trabalhos feitos do outro lado do Atlântico, Garnier havia contratado, para a revisão das obras portuguesas, "um dos melhores revisores que a nossa imprensa diária tem possuído" 42 .

Naquela altura, Machado provavelmente se referia ao poeta Bruno Henrique de Almeida Seabra, que, em 1862, embarcara para Paris, "contratado pela casa Garnier, como revisor do Jornal das Famílias e de livros em língua portuguesa impressos na França, de onde voltou em 1865 " ${ }^{43}$. Posteriormente, quem veio a exercer tal função foi José Lopes da Silva Trovão, expoente do movimento abolicionista e republicano histórico, que, depois de participar na Revolta do Vintém, passou alguns anos na capital francesa (só voltou ao Brasil já bem próximo da Proclamação da República), onde, além de trabalhar como revisor de provas da Garnier, atuou como correspondente do jornal O Globo e desempenhou a função de redator-chefe do periódico francês Chronique Franco-Brésilienne ${ }^{44}$. Todavia, após a morte de Baptiste-Louis em 1893 e o início da gestão de seu irmão François-Hypollite, num contexto de declínio e posterior recuperação da atividade editorial ${ }^{45}$, não se tem notícia de outro profissional que haja assumido tal empreitada.

\section{À GUISA DE UMA CONCLUSÃO}

Apesar de todas as deficiências e particularidades apontadas, o famigerado "cagara" e sua correção manual concentram as atenções dos bibliófilos, fazendo da segunda edição das Poesias Completas de Machado uma obra rara, muito mais procurada por eles do que a maioria dos outros títulos do escritor ${ }^{46}$. Esse processo de singularização de um livro e a paixão que um bibliômano sente ao adquirir tal item único já foram alvos da zombaria de Machado em suas Memórias Póstumas de Brás Cubas.

\footnotetext{
42. Machado de Assis, Obra Completa, p. 129.

43. Raimundo Magalhães Júnior, Vida e Obra de Machado de Assis - Ascensão, p. 180.

44. Ubiratan Machado, A Vida Literária no Brasil Durante o Romantismo, p. 102; Raimundo Magalhães Júnior, A Vida Turbulenta de José do Patrocínio, p. 80; Claudio H. M. Batalha, "Um Socialista Francês Diante da Escravidão no Brasil: Louis-Xavier de Ricard e o Jornal Le Sud-Américain”, p. 168.

45. Laurence Hallewell, O Livro no Brasil: Sua História, pp. 253-262.

46. Rizio Bruno Sant’Ana, “Como Definir Obras Raras: Critérios da Biblioteca Mário de Andrade”, p. 232.
} 
Achou o volume - por acaso, no pardieiro de um alfarrabista. Comprou-o por duzentos réis. Indagou, pesquisou, esgaravatou, e veio a descobrir que era um exemplar único... Único! Vós, que não só amais os livros, senão que padeceis a mania deles, vós sabeis mui bem o valor desta palavra, e adivinhais, portanto, as delícias de meu bibliômano. Ele rejeitaria a coroa das Índias, o papado, todos os museus da Itália e da Holanda, se os houvesse de trocar por esse único exemplar; e não porque seja o das minhas Memórias, fazia a mesma coisa com o Almanac de Laemmert, uma vez que fosse único ${ }^{47}$.

Para além de tal visão caricata do bibliômano, o narrador também se refere a essa figura como um amante dos livros (bibliófilo), que investiga, mediante uma combinação de excentricidade (mania), arte e soma de conhecimentos, o quão rara poderia ser a edição adquirida. Assim, para além do colecionismo, percebe-se que a raridade não seria um conceito dado de antemão ${ }^{48}$, mas um valor construído que estaria correlacionado à própria história de produção, circulação e apropriação de determinada obra.

Nesse ponto, portanto, a perspectiva e as preocupações do bibliófilo se cruzam com as do estudioso da relação entre a materialidade do texto e a textualidade do livro ${ }^{49}$. E, em linhas gerais, o que se procurou apresentar aqui, tendo em vista o exame de um caso específico, foram os resultados dessa intersecção: a partir, sobretudo, da especificidade e da concretude das edições raras das Poesias Completas de Machado colecionadas por Rubens Borba de Moraes e José Mindlin (e que também se fazem presentes em outros acervos), buscou-se recuperar o papel de um obscuro ator e discorrer sobre as condições técnicas, sociais e editoriais presentes no processo de publicação de tal livro no transcurso da passagem do século xIx para o Xx, no Brasil.

47. Machado de Assis, Memórias Póstumas de Brás Cubas, pp. 162-163.

48. Conforme destaca Chartier, "apesar de a raridade poder ser objetiva, ela é, de fato, com frequência construída. Um livro é raro a partir do momento em que há bibliófilos para procurá-lo" (cf. Roger Chartier, A Aventura do Livro: Do Leitor ao Navegador, p. 149).

49. Roger Chartier, Inscrever e Apagar, p. 13

\section{REFERÊNCIAS}

ANDRADE, Mário de. Aspectos da Literatura Brasileira. 5ª ed., São Paulo, Martins, 1974.

Assis, Machado de. Poesias Completas: Chrysalidas, Phalenas, Americanas e Occidentaes. Rio de Janeiro, H. Garnier, 1901. . Poesias Completas: Chrysalidas, Phalenas, Americanas e Occidentaes. Rio de Janeiro, H. Garnier, 1902. Poesias Completas: Chrysalidas, Phalenas, Americanas e Occidentaes. Rio de Janeiro, Livraria Garnier, 1924 (Coleção dos Autores Célebres da Literatura Brasileira). 
Poesias Completas: Crisálidas, Falenas, Americanas e Ocidentais. $2^{\text {a }}$ ed., Rio de Janeiro/

Brasília, Civilização Brasileira, INL, 1977.

. Poesias Completas. Rio de Janeiro, Livraria Garnier, 2000.

. A Poesia Completa: Edição Anotada e Recepção Crítica. Organização e fixação dos textos

de Rutzkaya Queiroz dos Reis. São Paulo, Nankin/Edusp, 2009.

Obra Completa. Rio de Janeiro, Nova Aguilar, 2008, vol. 4.

. Correspondência de Machado de Assis com Magalhães de Azeredo. Edição preparada por

Carmelo Virgílio. Rio de Janeiro, Instituto Nacional do Livro, 1969.

. Memórias Póstumas de Brás Cubas. São Paulo, Globo, 2008.

BAptista, Abel Barros. "A Reforma Hermenêutica. Acerca da Legibilidade de Dom Casmurro".

In: RochA, João Cezar de Castro (org.). Nenhum Brasil Existe - Pequena Enciclopédia. Rio de Janeiro, UniverCidade/Topbooks, 2003.

Autobibliografias. Campinas, Editora da Unicamp, 2003.

BARRERO, Marcos. "Um Escritor Incompreendido". O Estado de S. Paulo, 24 set. 1988, p. 4 (Caderno 2).

Batalha, Claudio H. M. "Um Socialista Francês Diante da Escravidão no Brasil: Louis--Xavier

de Ricard e o Jornal Le Sud-Américain”. In: VIDAL, Laurent \& LuCA, Tania Regina de

(orgs.). Franceses no Brasil: Séculos XIX-XX. São Paulo, Editora Unesp, 2009.

ChARTIER, Roger. A Aventura do Livro: Do Leitor ao Navegador. Trad. Reginaldo Carmello Corrêa de Moraes. São Paulo, Imprensa Oficial/Editora Unesp, 1998.

. Inscrever e Apagar. Trad. Luzmara Curcino Ferreira. São Paulo, Editora Unesp, 2007.

CoRdeIRo, Mário. "Um Dicionário à Procura de Seus Autores". Ilustração Brasileira, ano LXIv, n. 213, Rio de Janeiro, jan. 1953.

Fraga, Clementino. "Palavras do Senhor Clementino Fraga". Revista da Academia Brasileira de Letras, ano 51, vol. 84, jul.-dez. 1952.

Gonçalves, Fabiana. De Poeta a Editor de Poesia: A Trajetória de Machado de Assis para a Formação de Suas Poesias Completas. São Paulo, Cultura Acadêmica, 2015.

GRIECO, Agripino Grieco. Memórias. Rio de Janeiro, Conquista, 1972, vol. 2. . Machado de Assis, Rio de Janeiro, Livraria José Olympio Editora, 1959.

HALlewell, Laurence. O Livro no Brasil: Sua História. $2^{\mathrm{a}}$ ed. rev. e ampl. Trad. Maria da Penha Villalobos, Lólio Lourenço de Oliveira \& Geraldo Gerson de Souza. São Paulo, Edusp, 2005.

LAGo, Pedro Corrêa do. Brasiliana Itaú. Uma Grande Coleção Dedicada ao Brasil. São Paulo, Capivara, 2009.

Lemos, Eduardo. “O Homem da Porta da Garnier”. O Globo, 21 jun. 1939.

MACHADO de Assis: Primeiro Centenário - 1839-1939. S. 1., s. n., vol. 1, 1939. 3 vols.

MACHADO, Ubiratan. Machado de Assis: Roteiro da Consagração. Rio de Janeiro, Eduerj, 2003 . A Vida Literária no Brasil Durante o Romantismo. $2^{a}$ ed. rev. ampl. Rio de Janeiro, Tinta

Negra Bazar Editorial, 2010.

História das Livrarias Cariocas. São Paulo, Edusp, 2012.

MAgalhães Júnior, Raimundo. A Vida Turbulenta de José do Patrocínio. $2^{2}$ ed., São Paulo/ Rio de Janeiro, Livros Irradiantes S. A./Instituto Nacional do Livro, 1971. . Vida e Obra de Machado de Assis - Ascensão. Rio de Janeiro, Civilização Brasileira, 1981.

Mindlin, José. Uma Vida Entre Livros. São Paulo, Edusp/Companhia das Letras, 1997.

Montello, Josué. Diário da Manhã. Rio de Janeiro, Nova Fronteira, 1984.

Moraes, Rubens Borba de. O Bibliófilo Aprendiz. 4aㅡ ed. Brasília/Rio de Janeiro, Briquet de Lemos/Casa da Palavra, 2005.

“O Livro do DiA”. Gazeta de Notícias, 15 jun. 1912, p. 1.

PESQUisa de Filologia Fundação Casa de Rui Barbosa, "Sobre Esta Edição”. In: Assis, Machado de. Poesias Completas. Rio de Janeiro, Livraria Garnier, 2000.

SANT'ANA, Rizio Bruno. “Como Definir Obras Raras: Critérios da Biblioteca Mário de Andrade”. Revista da Biblioteca Mário de Andrade, vol. 54, jan.-dez. 1996.

SousA, José Galante de. Bibliografia de Machado de Assis. Rio de Janeiro, MEC/INL, 1955.

TORRES, Bolívar. "Livros com Erros Tipográficos São Cobiçados por Colecionadores",

O Globo, 22 abr. 2017. Disponível em: <https://oglobo.globo.com/cultura/livros/livros-comerros-tipograficos-sao-cobicados-por-colecionadores-21241389>. Acesso em: 10 out. 2017. 
“Uma Reportagem na Itália Constituiu um Grande Êxito de Livraria e de Crítica”. Correio Paulistano, 9 dez. 1939, p. 4. 